\title{
Functional and Genomic Changes in the Mouse Ocular Motor System in Response to Light Deprivation from Birth
}

\author{
Colleen A. McMullen, Francisco H. Andrade, and John S. Stahl \\ Department of Neurology, Case Western Reserve University and University Hospitals of Cleveland, Cleveland, Ohio 44106
}

Previous studies have suggested that abnormal visual experience early in life induces ocular motor abnormalities. The purpose of this study was to determine how visual deprivation alters the function and gene expression profile of the ocular motor system in mice. We measured the effect of dark rearing on eye movements, gene expression in the oculomotor nucleus, and contractility of isolated extraocular muscles. In vivo eye movement recordings showed decreased gains for optokinetic and vestibulo-ocular reflexes, confirming an effect of dark rearing on overall ocular motor function. Saccade peak velocities were preserved, however, arguing that the quantitative changes in these reflexes were not secondary to limitations in force generation. Using microarrays and quantitative PCR, we found that dark rearing shifted the oculomotor nucleus transcriptome to a state of delayed/arrested development. The expression of 132 genes was altered by dark rearing; these genes fit in various functional categories (signal transduction, transcription/translation control, metabolism, synaptic function, cytoskeleton), and some were known to be associated with neuronal development and plasticity. Extraocular muscle contractility was impaired by dark rearing to a greater extent than expected from the in vivo ocular motility studies: changes included decreased force and shortening speed and evidence of abnormal excitability. The results indicate that normal development of the mouse ocular motor system and its muscles requires visual experience. The transcriptional pattern of arrested development may indicate that vision is required to establish the adult pattern, but it also may represent the plastic response of oculomotor nuclei to abnormal extraocular muscles.

Key words: saccades; optokinetic reflex; vestibulo-ocular reflex; gene expression profiling; extraocular muscles; ocular motor system; eye movements

\section{Introduction}

The visual system is anatomically and functionally immature at birth; key properties such as binocularity and depth perception develop postnatally during a species-specific window called the "critical period" (Berardi et al., 2000). Interference with visual experience during this time leads to alterations in the vision processing centers (Fagiolini et al., 1994). Less clear is how abnormal sensory inputs early in life influence the ocular motor system. Previous studies suggested that normal visual experience during the critical period is necessary to calibrate the functional characteristics of the ocular motor system. For example, early visual deprivation alters the vestibular-ocular reflex (VOR) and the optokinetic response (OKR) in monkeys and rodents (Collewijn, 1977a; Favilla et al., 1984; Tusa et al., 2001). For the most part these deficits have been attributed to altered function of the central motor nuclei. However, there is evidence that the peripheral motor plant is disrupted also; for example, monocular lid closure in cats renders the extraocular muscles more fatigable (Lenner-

Received May 31, 2003; revised 0ct. 27, 2003; accepted 0ct. 28, 2003

This work was supported by the National Eye Institute (Grants EY12998 and EY13724 to F.H.A. and EY13370 to J.S.S.), by the Evenor Armington Fund, and by the Gene Expression Array Core Facility of the Comprehensive Cancer Center (P30 CA43703) and the Vision Science Research Center (P30EY11373) at Case Western Reserve University and University Hospitals of Cleveland.

Correspondence should be addressed to Francisco H. Andrade, Department of Neurology, University Hospitals of Cleveland, 11100 Euclid Avenue, Cleveland, 0H 44106. E-mail: fha@cwru.edu.

D0I:10.1523/JNEUROSCI.3234-03.2004

Copyright $\odot 2004$ Society for Neuroscience $\quad 0270-6474 / 04 / 240161-09 \$ 15.00 / 0$ strand and Hanson, 1979). It also has been shown that there is a critical period for rodent extraocular muscles during which normal visual and vestibular inputs are required for the expression of the extraocular muscle-specific myosin heavy chain (Brueckner and Porter, 1998; Brueckner et al., 1999). These results point to an important role for sensory experience in the normal development of the ocular motor system and its motor plant. Thus this study was designed to evaluate how visual deprivation early in life with a darkrearing protocol altered the functional characteristics and gene expression profile of the mouse ocular motor system. We combined in vivo eye movement recordings, in vitro extraocular muscle function, and gene expression profiling of oculomotor nuclei to obtain an integrative view of how the ocular motor system changes in response to dark rearing during the critical period. We found that, whereas compensatory eye movements were preserved qualitatively, there was an abnormal reduction in OKR and aVOR gains, likely because of the lack of visual feedback during the critical period. Correspondingly, the altered expression of genes characteristic of neuronal development and plasticity in the oculomotor nuclei from dark-reared mice suggested a state of delayed or arrested development. In addition, dark rearing induced significant functional alterations in the extraocular muscles, including weakness and evidence of abnormal excitability. The magnitude of these muscular deficits was greater than expected on the basis of the observed eye movement changes, suggesting that the central ocular motor controllers can compensate at least partially for the abnormal motor plant and lessen the effect of dark rearing. We conclude that normal visual experience is indeed 
necessary for the establishment of the functional properties of the ocular motor system.

\section{Materials and Methods}

Animals. Experimental use of C57BL mice (Jackson Labs, Bar Harbor, ME) was approved by the Institutional Animal Care and Use Committee at Case Western Reserve University and conformed to National Institutes of Health guidelines for the use and care of vertebrate animals. Timed pregnant mice (gestational day 18) were housed either in a room with a $12 \mathrm{hr}$ light/dark cycle or in a room sealed from visible light. After birth, dark rearing of whole litters was maintained for the entire 8 week duration of the study, which included the postnatal critical period of visual system development. This intervention has been shown to delay the maturation of the visual cortex and disrupt the expression of extraocular muscle-specific myosin (Brueckner and Porter, 1998; Berardi et al., 2000). Animal care and husbandry were performed under brief $(\leq 10$ $\mathrm{min} / \mathrm{d}$ ) low-intensity red light illumination (Kodak 1A filter, Rochester, NY), which is below the sensitivity threshold for the rodent visual system (Brueckner and Porter, 1998). Age-matched control mice were drawn from litters housed under standard lighting conditions. For tissue isolation the mice were anesthetized with ketamine/xylazine $(80 / 10 \mathrm{mg} / \mathrm{kg}$, i.p. injection) and killed by exsanguination after a medial thoracotomy. Extraocular muscles were dissected intact, including a fragment of bony origin and distal tendon for attachment to a force transducer and servomotor (see below). For isolation of oculomotor nuclei, 1-mm-thick sagittal sections of brainstem ( $0.5 \mathrm{~mm}$ on either side of the midline) were cut. Oculomotor nuclei were identified as the oval gray matter $0.3 \mathrm{~mm}$ ventral to the aqueduct of Sylvius, quickly isolated, and frozen in liquid nitrogen for storage at $-80^{\circ} \mathrm{C}$.

Ocular motor function. Eye movement recordings were obtained in eight dark-reared and six control mice with the use of techniques previously described (Stahl et al., 2000; Stahl, 2002). Briefly, the animals were prepared several days before the first recordings by surgically implanting an acrylic head fixation pedestal under halothane anesthesia. The pedestal was positioned to maintain the head in a natural position in which a line drawn from the inner to the outer canthus would be in, or pitched slightly down from, the earth-horizontal plane. Animals were maintained in darkness except during recordings and for a few moments before and after surgical preparation. Before each recording session the recorded eye was pretreated with $0.5 \%$ physostigmine ophthalmic drops to limit pupil dilation in darkness. During recordings the animal's body was restrained loosely in an acrylic tube with the pedestal securely bolted to an extension of the tube. The assembly was mounted on a turntable and enclosed completely in a drum painted with a highly contrasted pattern. Vestibular or optokinetic stimulation about an earth-vertical axis was accomplished by manual or computer-controlled rotation of the table or drum, respectively. A modified commercial video oculography system (ETL200, ISCAN, Burlington, MA) was used to track the position of the pupil centroid and a reference corneal reflection at rates of 60 or 120 samples/sec (the higher rate being reserved for recording fast phases). The $x-y$ positions of the pupil and reference reflection subsequently were converted to angular eye-in-head position, using a trigonometric algorithm as previously described (Stahl et al., 2000; Stahl, 2002). Briefly, the trigonometric algorithm is based on knowing $R_{\mathrm{p}}$, the distance between the plane of the pupil and the center of corneal curvature. $R_{\mathrm{p}}$ is determined from the relative motion of the pupil and corneal reflection centroids as the video camera is rotated around the stationary animal over a known angle. Because $R_{\mathrm{p}}$ is sensitive to pupil diameter (it decreases as the pupil enlarges), the determination is performed at various pupil sizes (achieved by varying illumination levels), and linear regression is used to generate an equation relating pupil diameter to $R_{\mathrm{p}}$ (Stahl, 2002). During data collection the pupil diameter is stored along with pupil and reference reflection positions. Then the pupil position is used to generate an instantaneous value for $R_{\mathrm{p}}$, which in turn is used to convert the separation of the pupil and corneal reflection centers to eye-in-head angle.

Horizontal fast phases were generated by slowly rotating the animal under manual control in the light. The experimenter monitored the image of the eye and adjusted the rotation speed and direction to generate a range of fast-phase amplitudes as well as to ensure that eye velocity was low at the moment of fast-phase initiation. Eye velocity was calculated off-line by differentiating the eye position signal. Candidate fast phases were identified by using a supervised automated program. The program searched the records for moments at which eye velocity surpassed $40 \%$ $\mathrm{sec}$. The onsets and offsets of each candidate fast phase then were defined by searching forward and backward from the $40 \%$ sec point for the moments at which eye velocity fell below $5 \% \mathrm{sec}$. The candidate fast phases and their onsets/offsets were reviewed, and candidates were excluded from analysis if they were disrupted by tracking instabilities or if they were felt to represent slow-phase movements. (Because of the intentional sensitivity of the algorithm, it could identify erroneously "post-saccadic" drifts or rapid slow phases as fast phases.) Linear regression was used to extract the slope of the relationship between peak velocity and fast-phase amplitude, with the regression forced to pass through the origin. Abducting and adducting fast phases were treated separately. Values for each animal were based on the average of values obtained from at least two recording sessions performed on different days.

In addition to determining fast-phase dynamics, we also assessed in the same animals the integrity of the mechanisms underlying compensatory eye movements by determining speed tuning curves for the OKR and gains and phases of the angular VOR (aVOR). The aVOR was probed by using sinusoidal rotation in darkness at $0.2 \mathrm{~Hz} \pm 10^{\circ}$ amplitude, 0.4 $\mathrm{Hz} \pm 10^{\circ}$ amplitude, and $1.6 \mathrm{~Hz} \pm 4^{\circ}$ amplitude. aVOR gain and phase with respect to the stimulus were extracted in the conventional manner; table (head) velocity and eye-in-head velocity were calculated by taking the derivatives of the respective angular position signals. Fast phases of vestibular nystagmus were identified by using velocity criteria and were replaced with simulated slow-phase movements (generated by interpolating from the slow-phase movements immediately flanking the fast phases) (Stahl, 2002). Records then were divided into individual cycles and pointwise averaged to generate a single average cycle of eye velocity and head velocity. Then the amplitude and phase of these averaged curves were extracted by Fourier decomposition. Finally, gain was calculated as the ratio of the amplitude of the eye and table velocities, and phase was calculated as the difference of their phases. OKR was tested in response to a series of $4 \mathrm{sec}$ periods of constant velocity drum rotation at $\pm 2.5,5,10,20$, and $40^{\circ} / \mathrm{sec}$, each separated by $3.5 \mathrm{sec}$ periods during which the drum accelerated to a stable velocity with the animal in darkness. For each period of constant velocity drum rotation in the light, fast phases were detected by using velocity criteria and removed; the gap in the data was filled by interpolating from the flanking slow-phase movements. Then the average velocity for the period was calculated. Gain was calculated as the ratio of the average eye and drum velocities. Three to four records were collected per session, and the gains at each stimulus velocity were averaged to generate a gain versus stimulus velocity curve for the session. At least two sessions were performed on different days for each animal, and the resultant curves were averaged to generate a single curve per animal.

Gene expression changes. High-density oligonucleotide microarray studies were conducted as described earlier (Porter et al., 2001). Briefly, total RNA was obtained from oculomotor nuclei isolated from control and light-deprived mice with Trizol reagent (Invitrogen, San Diego, CA) by following the manufacturer's protocol; nuclei from four to five animals were combined into each independent total RNA sample to lessen the effect of inter-subject variability. Then double-stranded cDNA, including a T7 RNA polymerase promoter site, was prepared. Biotinylated complementary cRNA was transcribed from the cDNA and hybridized to Affymetrix Murine Genome U74Av2 GeneChips ( $~ 6000$ known genes and $\sim 6000$ expressed sequence tags, ESTs). Then the microarrays were washed and stained with a streptavidin-bound marker and scanned with a laser scanner. Resulting microarray data were analyzed with Affymetrix Microarray Suite 5.0 software. To test the integrity of the starting RNA, we examined the signal intensity ratio for the $3^{\prime}$ probe set over the $5^{\prime}$ probe set for the housekeeping genes $\beta$-actin and glyceraldehyde-3phosphate dehydrogenase (GAPDH). Affymetrix recommends that samples with ratios higher than 3 or inconsistent between samples be discarded. For the six arrays used in this study, the $3^{\prime}-5^{\prime}$ ratios were $1.3 \pm$ 0.06 and $0.97 \pm 0.08$ for $\beta$-actin and GAPDH, respectively. Once sample quality was demonstrated, those genes with consistent absent/present calls in the three independent replicates per group were considered for 
further analyses. Treatment comparisons were crossed such that each dark-reared sample was compared with each control $(3 \times 3$ matrix $)$.

The Affymetrix software uses the one-sided Wilcoxon's signed rank test to estimate the statistical significance of "increase/no change/decrease" difference calls and fold changes for each pairwise comparison. Only difference calls (increase or decrease) with $p<0.05$, consistent across all pairwise comparisons and with average changes more than or equal to twofold, were considered significant. This approach resulted in a conservative list of genes with changed expression levels. GeneSpring v4.2 (Silicon Genetics, Redwood City, CA) was used to construct hierarchical clusters of gene probes identified as being differentially expressed. GeneSpring and Cluster v2.20 (available from www.rana.lbl.gov/EisenSoftware.htm) were used to determine whether certain gene clusters or classes were particularly more influential in explaining the effect of dark rearing; principal component analysis (PCA) was performed on mean-centered log-transformed data (Eisen et al., 1998). Known or putative gene functions were determined from gene ontology classifications from Affymetrix (www.NetAffx.com), Online Mendelian Inheritance in Man (www.ncbi.nlm.nih.gov/omim), and Mouse Genome Informatics (www.informatics.jax.org), and from references listed in GenBank entries (www.ncbi.nih.gov/Genbank/).

To confirm the microarray data, we studied selected genes in oculomotor nuclei from control and dark-reared mice by real-time quantitative PCR (qPCR). Reverse transcription was performed by using Superscript II RNase $\mathrm{H}^{-}$Reverse Transcriptase (Invitrogen, Carlsbad, CA) with oligo- $\mathrm{dT}_{12-18}$ primers or random hexamers. Primers for the mRNAs of interest were designed with the software package Primer Express version 1.5 (Applied Biosystems, Foster City, CA) from GenBank nucleotide sequences (Table S1; available at www.jneurosci.org). cDNA samples (1 $\mu \mathrm{g}$ each) were analyzed in triplicate with the ABI Prism 7700 Sequence Detection System (Applied Biosystems) by using the ABI SYBR Green Master Mix kit and $\beta$-actin as the calibrator housekeeping gene. The relative abundance of target mRNAs in oculomotor nuclei from control and dark-reared mice was determined with the comparative cycle threshold method (Giulietti et al., 2001; Livak and Schmittgen, 2001).

Extraocular muscle function. Whole extraocular muscles from darkreared and age-matched control mice were studied within $3 \mathrm{~d}$ after the completion of 8 weeks of dark rearing. Isolated muscles were attached firmly to a force transducer (AE801, SensoNor, Horten, Norway) and the movable arm of a servomotor (Aurora Scientific, Aurora, Canada) and positioned between platinum electrodes inside a muscle chamber. The chamber was superfused with a physiological salt solution (in mM): 137 $\mathrm{NaCl}, 5 \mathrm{KCl}, 2.0 \mathrm{CaCl}_{2}, 1.0 \mathrm{MgSO}_{4}, 1.0 \mathrm{Na}_{2} \mathrm{HPO}_{4}, 24 \mathrm{NaHCO}_{3}, 11$ glucose, and $0.026 d$-tubocurarine, bubbled with a $95 \% \mathrm{O}_{2} / 5 \% \mathrm{CO}_{2}$ gas mixture to maintain $\mathrm{pH} 7.4$ at $25^{\circ} \mathrm{C}$. Muscles were stretched to the length giving maximum tetanic force (optimal length, $L_{0}$ ). Force measurements (in Newtons) were normalized to muscle cross-sectional area $\left(\mathrm{cm}^{2}\right)$. The unloaded shortening velocity $\left(V_{0}\right)$ of isolated extraocular muscles was determined with slack tests (Claflin and Faulkner, 1985). Briefly, muscles were stimulated to contract maximally for $350 \mathrm{msec} ; 250 \mathrm{msec}$ into the stimulation train the muscle was shortened abruptly, causing force to fall to zero. The time to take up the slack and redevelop force was measured after rapid releases of at least four different amplitudes (between 5 and $11 \%$ of $L_{0}$ ) performed in consecutive tetani at $2 \mathrm{~min}$ intervals. $V_{0}$, in $L_{0} / \mathrm{sec}$, was calculated as the slope of the linear regression line in plots of the release amplitude versus the time to take up the slack. After we measured all other functional properties, fatigue was induced by stimulating muscles at a frequency giving approximately one-half of maximal tetanic force $(50-70 \mathrm{~Hz})$ for $500 \mathrm{msec}$, followed by a $1.5 \mathrm{sec}$ interval between contractions for $10 \mathrm{~min}$.

Data analysis. All results are presented as means \pm SEM of $n$ observations, unless otherwise noted. Statistical significance was determined at the $95 \%$ confidence level by Student's $t$ test for either unpaired or paired samples as indicated; the treatment effect in the fatigue runs was determined by ANOVA.

\section{Results}

Effects of dark rearing on eye movements

Figure 1 shows a typical velocity/amplitude plot constructed from 123 fast phases. Velocity/amplitude relationships exhibited

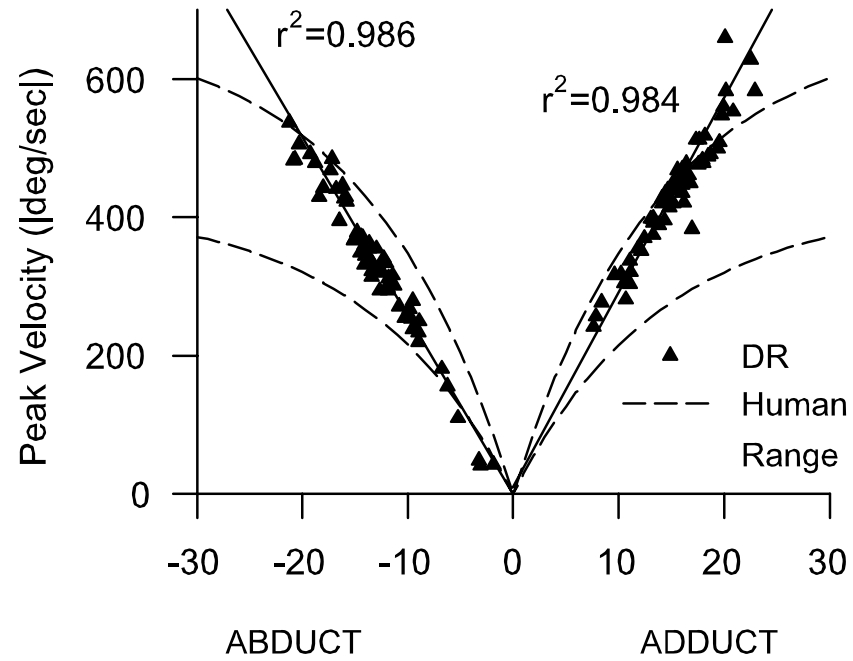

Fast Phase Amplitude (deg)

Figure 1. Absolute value of peak velocity of fast phases (generated by slow rotation of the animal in the light) plotted versus amplitude for 123 fast phases collected in one recording session from a typical dark-reared animal (DR). Linear regression fits (forced to pass through the origin) and associated correlation coefficients are superimposed (solid lines). The confidence interval ( \pm 2 SD) for normal humans (Baloh et al., 1975) also is included (dashed lines) for reference. Velocity/amplitude relationships for both dark-reared and control animals exhibited a high degree of linearity and uniformity.

a high degree of uniformity and linearity for both light-deprived and control animals. Unlike velocity/amplitude plots in primates (Fuchs, 1967; Boghen et al., 1974; Baloh et al., 1975) and headfree rabbits (Collewijn, 1977b) but similar to those reported for cats (Evinger and Fuchs, 1978; Harris and Cynader, 1981) and guinea pigs (Escudero et al., 1993), there was no tendency for velocity to saturate with increasing fast-phase amplitude, at least within the range of fast-phase amplitudes we were able to elicit (typically no more than $25-30^{\circ}$ ). Dark-reared and control animals exhibited equivalent velocity/amplitude slopes averaging $24.7 \pm 1.1$ versus $24.1 \pm 1.3 / \mathrm{sec}$ (mean \pm SD) for abduction and $27.4 \pm 1.1$ versus $27.7 \pm 1.0 / \mathrm{sec}$ for adduction. Differences between test and control animals were not statistically significant ( $p=0.32$ and 0.60 , respectively; two-tailed unpaired $t$ test). On the other hand, the higher speed of the adducting fast phases was statistically significant for both animal groups $(p<0.0001$ and $p=0.00012$, respectively; two-tailed paired $t$ test).

Dark rearing induced mild but consistent abnormalities of horizontal aVOR and OKR. In the dark-reared animals aVOR gains at $0.2,0.4$, and $1.6 \mathrm{~Hz}$, respectively, averaged $0.04 \pm 0.02$, $0.17 \pm 0.07$, and $0.52 \pm 0.10$. In contrast, the control animals yielded gains of $0.29 \pm 0.12,0.63 \pm 0.11$, and $0.77 \pm 0.10$. The inter-group differences were significant at 0.0001 or better for all three of the stimulus frequencies. The degree to which the phase of eye velocity led head velocity was also abnormally large in the dark-reared group. For example, at $0.4 \mathrm{~Hz}$ the phase lead averaged $45.5 \pm 13.6^{\circ}$ versus $17.2 \pm 3.0^{\circ}$ for the dark-reared and control groups, respectively $(p=0.0003)$. The corresponding phase values at $0.4 \mathrm{~Hz}$ correlated significantly with gain for the dark-reared, but not for the control, animals (regression slope, $m=160.9^{\circ}, r^{2}=0.653, p=0.015$ for the dark-reared group vs $m=20.0^{\circ}, r^{2}=0.503, p=0.115$ for controls).

Figure 2 shows the OKR speed tuning curves for the two groups. Control animals exhibited optokinetic gains that neared 0.8 at the lowest drum speeds, declining steadily at stimulus 


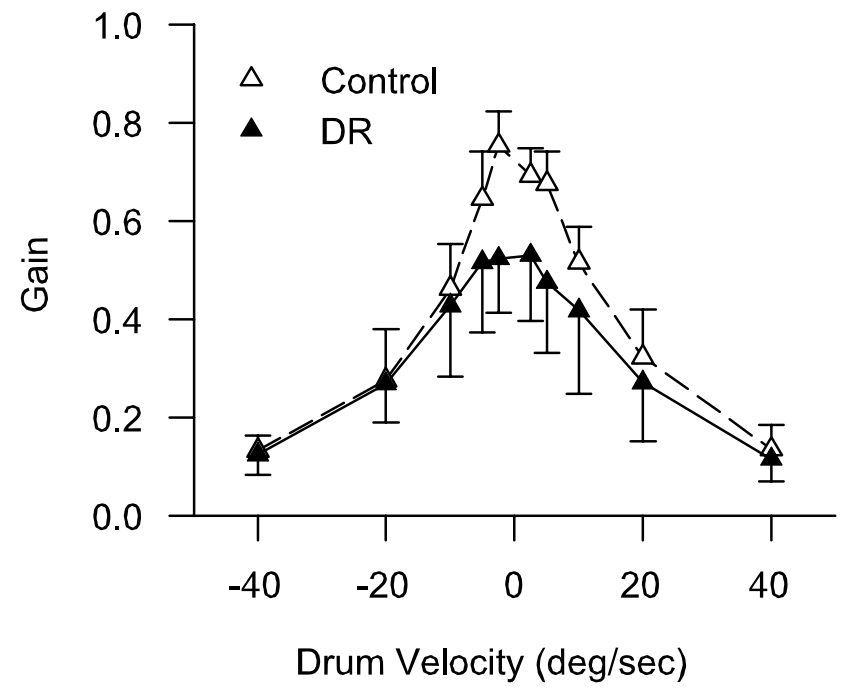

Figure 2. Plot of horizontal optokinetic reflex gain versus stimulus velocity. Control and dark-reared (DR) animals are plotted as open and filled triangles, respectively. Error bars span 1 SD. Although the dark-reared animals generated compensatory eye movements in response to visual stimulation, their OKR gains were attenuated in comparison to controls, particularly at low stimulus velocities.

speeds above $5 \%$ sec. OKR gain was reduced in the dark-reared group, most noticeably at the lower drum speeds. Averaging the gains in response to leftward and rightward drum rotation at $5 \% \mathrm{sec}$ yielded values of $0.50 \pm 0.13$ for the light-deprived and $0.66 \pm 0.08$ for the control animals $(p=0.015)$. OKR gains for \pm $5 \% \mathrm{sec}$ and VOR gains for $0.4 \mathrm{~Hz}$ stimulation tended to correlate positively in dark-reared animals $\left(m=1.2, r^{2}=0.404, p=0.09\right)$, but not in controls $\left(m=-0.38, r^{2}=0.272, p=0.289\right)$.

Effects of dark rearing on oculomotor gene expression profile We determined the effect of dark rearing on the gene expression profile of mouse oculomotor nuclei with high-density oligonucleotide microarrays that interrogate 12,451 genes and ESTs. Of these, $51.8 \pm 0.8$ and $52.2 \pm 1.0 \%$ were present in the samples from control and dark-reared mice, respectively. Data analysis was conservative; only those genes with the same present/absent call in all replicates were considered. Thus the fraction of genes consistently identified as present was $47 \%$ in both groups: 5872 and 5928 for control and dark-reared, respectively. The high proportion of present calls is also an indication of good sample quality. Changes were considered valid only when the same qualitative result (increase or decrease call with $p<0.05$ ) was obtained in all pairwise comparisons and when the average fold difference value was $\geq 2$.

\section{Overall shift in gene expression}

The expression of 132 genes and ESTs was altered by dark rearing; 106 were upregulated and 26 downregulated (Fig. 3A). For descriptive purposes products were assigned to categories on the basis of their known function as determined by literature and gene ontology database searches: $7 \%$ were related to the cytoskeleton, $13 \%$ to metabolism, $10 \%$ to synaptic function and excitability, $20 \%$ to signal transduction, and $11 \%$ to gene transcription and translation; $14 \%$ did not fit these classes or were unknown, and $25 \%$ were ESTs (Fig. 3B). Importantly, the results did not determine which genes, clusters, or functional classes may be mechanistically more important to achieve the final transcriptome. The complete list of genes and ESTs changed by dark rearing is available as supplemental data (Table S2; available at www. jneurosci.org). PCA identified two components: the first
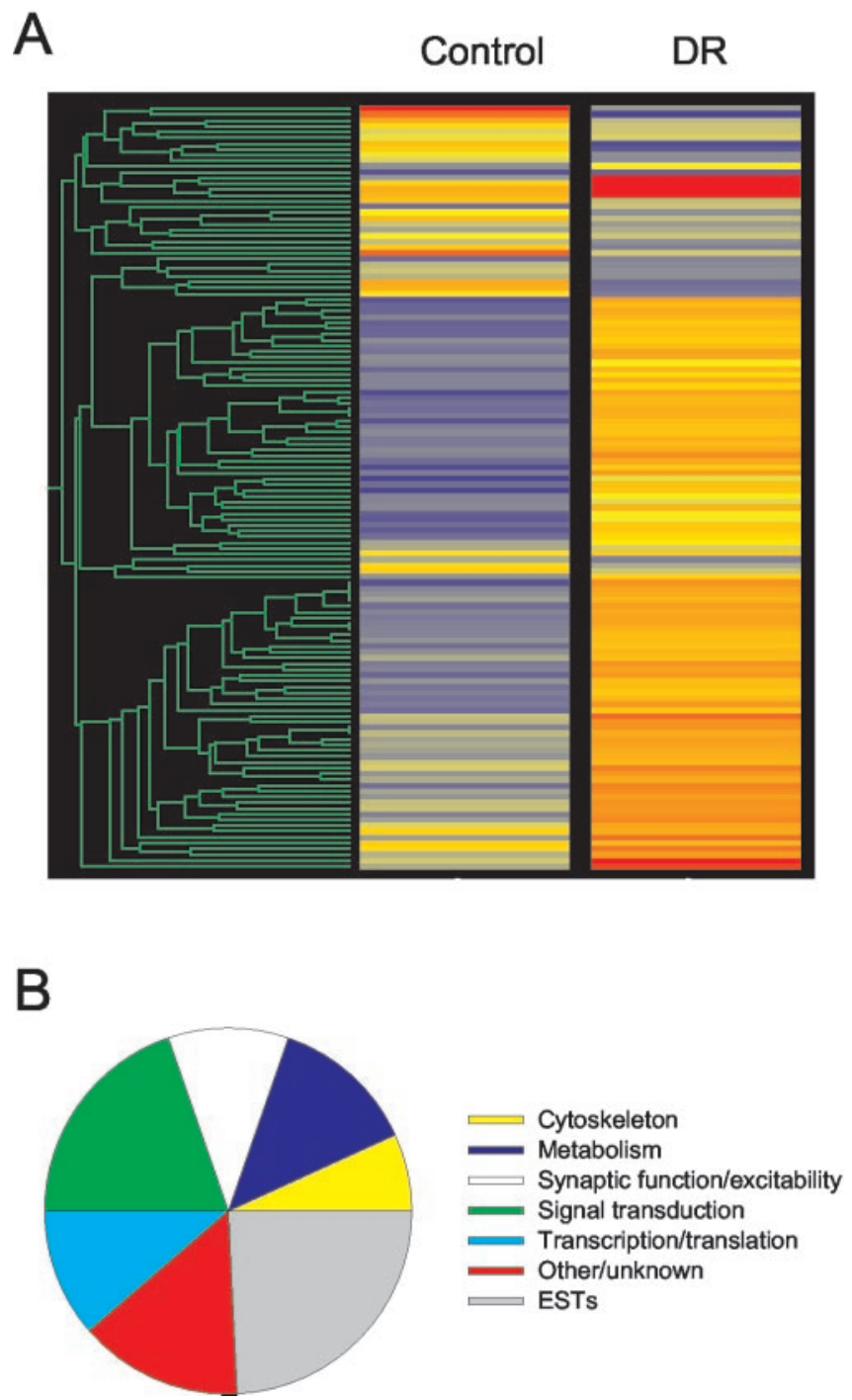

Figure 3. A, Hierarchical clusters showing the effect of dark rearing on the gene expression profile of mouse oculomotor nuclei. Values are based on average fluorescence intensity differences between the control and dark-reared groups ( $n=3$ microarrays per group). Changes in expression are color-coded: relative gene expression levels increase from blue to red; genes upregulated by dark rearing go deeper into yellow and red. $B$, Chart illustrating the proportion of genes for which the expression was altered by dark rearing in the respective functional categories. Assignment was based on information from public access gene ontology databases.

component was an average expression weighted by the overall experimental variance $\left(r^{2}=0.83\right)$; the orthogonal second component explained the treatment variance $\left(r^{2}=0.17\right)$. Plotting the genes against the two principal components gave an ellipse including $100 \%$ of the genes; no groups could be identified (data not shown). This unimodal distribution of expression in the two dimensions given by the principal components indicated that the genes do not fall into well defined clusters.

\section{Gene expression patterns}

Thirty-one genes that responded to dark rearing have been reported previously to participate in neuronal development and plasticity in other sensory and motor systems. Table 1 presents this subset of genes in bold typeface. Most of these genes were upregulated by dark rearing. Although they share the common developmental thread, the genes were assigned to different functional categories on the basis of the information from the gene ontology databases, with the majority being involved in signal 
transduction and the control of gene translation and transcription. Five genes with increased expression are related to apoptosis and cell proliferation: CAS9, GAS2, JNK1, 14-3-3 $\eta$, and WBSCR9. Dark rearing also upregulated the expression of cytoskeletal proteins (KIF5A and KIF5C) and decreased mitochondrial markers such as ubiquitous mitochondrial creatine kinase. KIF5 isoforms appear in mouse oculomotor nuclei (cranial nerves 3, 4, and 6) at 2 weeks of age and seem to be important for the preservation of motor neurons (Niclas et al., 1994). This is also the proposed function for GFRA2 in oculomotor neurons (Hashino et al., 2001).

Genes involved in cell-cell interactions and myelination also were affected by dark rearing: CLDN 11 and desmocollin 2, which exert a positive effect on these processes, were downregulated; the antagonistic cytohesin-1 was upregulated. Other markers typical of neuronal development and proliferation were upregulated in the oculomotor nuclei from dark-reared mice: GLUT3, NOS1, ARNT2, TBR1, NRF1, RIP15, POLR2A, WNT7B, and ZNF179. Similarly, 11 genes previously found to be related to synaptic organization and function were upregulated by dark rearing. These included genes coding for the cytoskeletal scaffold that participates in the intracellular movement of synaptic vesicles $(\mathrm{KIF} 1 \mathrm{~B} \beta)$ and the vesicle-associated proteins VAMP1, VAMP3, and synaptobrevin 1. Syntaxin, the binding partner for synaptobrevin in the presynaptic membrane, also was detected at higher levels in the dark-reared group. Finally, dark rearing increased the expression of the vesicletrafficking regulators ARF3 and ARF1.

To confirm the microarray data, we analyzed 15 of the genes listed in Table 1 ( $\sim 11 \%$ of the 132 genes changed) by qPCR; the

Table 1. Differential gene expression in mouse oculomotor nucleus after dark rearing

\begin{tabular}{|c|c|c|c|c|}
\hline \multirow[b]{2}{*}{ GenBank no. } & \multirow[b]{2}{*}{ Gene name } & \multicolumn{3}{|c|}{ Fold change ( $p$ value) } \\
\hline & & Microarray & $q P C R$ & Reference \\
\hline \multicolumn{5}{|c|}{ Cytoskeleton } \\
\hline D29951 & Kinesin heavy chain 1B (KIF1B) & $3.4(0.042)$ & & (Nangaku et al., 1994) \\
\hline AF067180 & Kinesin heavy chain 5C (KIF5C) & $2.4(0.049)$ & $5.9(0.024)$ & (Niclas et al., 1994) \\
\hline AB023656 & Kinesin heavy chain 1B- $b$ (KIF1B- $\beta)$ & $2.3(0.042)$ & $8.0(0.004)$ & (Nangaku et al., 1994) \\
\hline AF053473 & Kinesin heavy chain 5A (KIF5A) & $2.0(0.021)$ & & (Niclas et al., 1994) \\
\hline \multicolumn{5}{|c|}{ Metabolism } \\
\hline Al848335 & NEDD-4 protein & $2.3(0.011)$ & $9.8(0.016)$ & (Flasza et al., 2002) \\
\hline M75135 & Glucose transporter 3 (GLUT3) & $2.1(0.024)$ & & (Chairi et al., 2002) \\
\hline Z13968 & Mitochondrial creatine kinase, ubiquitous & $-2.6(0.025)$ & & (Payne and Strauss, 1994) \\
\hline \multicolumn{5}{|c|}{ Signal transduction } \\
\hline D87900 & ADP-ribosylation factor 3(ARF3) & $3.3(0.033)$ & $1.8(0.11)$ & (Irobi et al., 2002) \\
\hline D14552 & Nitric oxide synthase 1 (NOS1) & $3.1(0.03)$ & & (Baxter et al., 2002) \\
\hline AF051337 & Cytohesin-1 (PSCD1) & $3.0(0.025)$ & & (Moss and Vaughan, 2002) \\
\hline NM 008087 & Growth arrest-specific 2 (GAS2) & $2.9(0.022)$ & $2.2(0.01)$ & (Brancolini et al., 1992) \\
\hline AF001871 & ADP-ribosylation factor 1 (ARF1) & $2.8(0.027)$ & $3.4(0.043)$ & (Crottet et al., 2002) \\
\hline X90648 & Crkl protein & $2.5(0.026)$ & $52(0.033)$ & (Lekmine et al., 2002) \\
\hline M89802 & Wingless-type MMTV integration site family, member 7b (WNT-7B) & $2.5(0.019)$ & & (Parr et al., 2001) \\
\hline U37017 & VAV2 & $2.4(0.006)$ & & (Abe et al., 2000) \\
\hline AJ223834 & G-protein-coupled receptor 37 (GPR37) & $2.3(0.041)$ & & (Marazziti et al., 1998) \\
\hline AB005663 & c-Jun kinase 1 (JNK1) & $2.3(0.037)$ & $9.2(0.047)$ & (Kaminska et al., 1999) \\
\hline U56243 & 14-3-3 $\eta$ (brain isoform) & $2.3(0.046)$ & $239(0.027)$ & (Malaspina et al., 2000) \\
\hline AF002701 & GDNF family receptor a2 (GFRA2) & $2.0(0.04)$ & & (Hashino et al., 2001) \\
\hline U89527 & Neuronal CDK5 activator (NCK5A) & $2.0(0.016)$ & $2.9(0.027)$ & (Chae et al., 1997) \\
\hline \multicolumn{5}{|c|}{ Synaptic function/excitability } \\
\hline D29743 & Syntaxin $1($ STX1b) & $3.6(0.013)$ & $16(<0.0001)$ & (Jarvis et al., 2002) \\
\hline X51986 & GABA receptor $\alpha-6$ subunit (GABR-A6) & $3.2(0.027)$ & & (Brickley et al., 2001) \\
\hline U13836 & Vacuolar ATPase subunit Ac116 & $2.9(0.025)$ & & (Gall et al., 1996) \\
\hline X16645 & $\mathrm{Na}^{+} / \mathrm{K}^{+}$ATPase, $\beta$-2 subunit (ATP1B2) & $2.9(0.034)$ & & (Lecuona et al., 1996) \\
\hline D10028 & Glutamate receptor channel, subunit $\zeta-1$ (GLURZ1) & $2.7(0.027)$ & & (Yamazaki et al., 1992) \\
\hline U61751 & Synaptobrevin 1 (VAMP1) & $2.5(0.04)$ & $4.9(0.049)$ & (Bhattacharya et al., 2002) \\
\hline Al847972 & Vesicle-associated membrane protein 3 (VAMP3) & $2.3(0.011)$ & $4.3(<0.001)$ & (0lson et al., 1997) \\
\hline D38614 & Presynaptic protein $921-5$ & $2.2(0.042)$ & & (Takahashi et al., 1995) \\
\hline U60150 & Vesicle-associated membrane protein 1 (VAMP2) & $2.0(0.04)$ & & (Quetglas et al., 2002) \\
\hline \multicolumn{5}{|c|}{ Gene transcription/translation } \\
\hline M88299 & Brain-1 class III PoU-domain & $3.4(0.017)$ & & (Hara et al., 1992) \\
\hline D63644 & AhR receptor nuclear translocator 2 (ARNT2) & $3.0(0.043)$ & & (Petersen et al., 2000) \\
\hline AF084480 & Williams-Beuren syndrome deletion transcript 9 (WBSCR9) & $2.7(0.018)$ & & (Horie et al., 1999) \\
\hline U49251 & Brain T-box 1 (TBR1) & $2.4(0.027)$ & & (Bulfone et al., 1995) \\
\hline AF015881 & Nuclear factor erythroid-related 1 (NRF1) & $2.4(0.017)$ & $6.5(0.022)$ & (Prieschl et al., 1998) \\
\hline AB013097 & Zinc finger protein 179 (ZNF179) & $2.3(0.042)$ & & (Orimo et al., 1998) \\
\hline U09419 & Retinoid X receptor interacting protein (RIP15) & $2.1(0.046)$ & $6.3(0.002)$ & (Seol et al., 1995) \\
\hline Z47088 & RNA polymerase II, subunit A (POLR2A) & $2.0(0.047)$ & & (Buratowski, 1994) \\
\hline \multicolumn{5}{|c|}{ Other/unknown } \\
\hline AB01960 & Caspase 9 (CAS 9) & $2.8(0.034)$ & & \\
\hline AF052506 & RNA-specific adenosine deaminase (ADAR) & $2.6(0.032)$ & & (Bass, 2002) \\
\hline U19582 & Claudin 11 (CLDN11) & $-2.0(0.01)$ & & (Bronstein et al., 2000) \\
\hline X58196 & H19 & $-2.3(0.041)$ & & (Poirier et al., 1991) \\
\hline AW228162 & Desmocollin 2 & $-2.4(0.024)$ & & (Bloor et al., 2002) \\
\hline
\end{tabular}


results are included as an additional column in the same table. Fourteen genes showed the same qualitative response by qPCR; however, we were unable to confirm the microarray result for ARF3 (1.8-fold increase by qPCR; $p>0.05$ ). On the basis of the statistical analysis, we would expect that $5 \%$ of genes determined to be altered by dark rearing would be false positives. The qPCR data confirmed 14 of 15 genes that were studied, giving a false positive rate of $<7 \%$ and reinforcing the confidence on the robustness of the microarray results.

\section{Effects of dark rearing on extraocular muscle function}

Abnormal visual experience alters some functional and biochemical properties of the extraocular muscles, the final motor component of the ocular motor system (Lennerstrand and Hanson, 1979; Brueckner and Porter, 1998). To determine whether the motor deficits observed in the in vivo eye movement studies reflected changes in the functional properties of the extraocular muscles, we evaluated the contractile characteristics of these muscles. Dark rearing altered the contractile properties of mouse extraocular muscles: the maximal tetanic force $\left(P_{0}\right)$ that muscles can generate decreased by $\sim 11 \%(5.3 \pm 0.2$ vs $4.7 \pm 0.1$ Newtons $/ \mathrm{cm}^{2}$ for control and dark-reared groups, respectively; $n=$ 10 muscles/group; $p<0.001$ ), and the maximal velocity of unloaded shortening $\left(V_{0}\right)$ decreased by almost $20 \%$ (Fig. 4 ). A very intriguing finding was the peculiar response of most extraocular muscles from dark-reared mice to a standard in vitro fatigue protocol. When muscles are stimulated repeatedly with submaximal stimulation frequencies (not fully fused tetani), force typically increases during the first few minutes (potentiation) and then decreases monotonically, as demonstrated for the control extraocular muscles (Fig. 5A). In this study only one extraocular muscle from the dark-reared group presented this fatigue pattern (black circles, Fig. 5B). Two muscles in this group had dramatic drops in force production early in the fatigue protocol and remained at this depressed level for the remainder of the fatigue protocol (e.g., white triangles in Fig. 5B). Most extraocular muscles in the light-deprived group (7 of 10 muscles) presented seesaw fluctuations in force production during the fatigue protocol (e.g., line in Fig. $5 B$ ). It is important to note that these were not force oscillations during a single contraction; rather, the data represent peak forces produced during separate contractions. Therefore, each tetanus during these episodes had a normal appearance; this is illustrated in Figure $5 C$, which shows original records of tetani at specified time points during the fatigue protocol. The amplitude of the tetani changed over time in a seesaw pattern, the force generated at the conclusion of the fatigue protocol by the dark-reared muscles showing this pattern was greater than for the control muscles $(58.7 \pm 2.6$ and $52.5 \pm 1.6 \%$ of initial dark-reared vs control; $p<0.05)$.

\section{Discussion}

Dark rearing explores the experience-dependent plasticity in the visual system (Berardi et al., 2000). This study is the first to use this intervention to determine the effects of abnormal sensory input on the gene expression profile and function of the murine ocular motor system. Our findings indicate that light deprivation early in life alters central and peripheral ocular motor function and shifts the gene expression pattern of oculomotor nuclei to a profile consistent with delayed or arrested maturation.

\section{Light deprivation alters ocular motor function}

Recordings of aVOR and OKR indicated that dark-reared mice retain the eye movements that stabilize the visual world on the

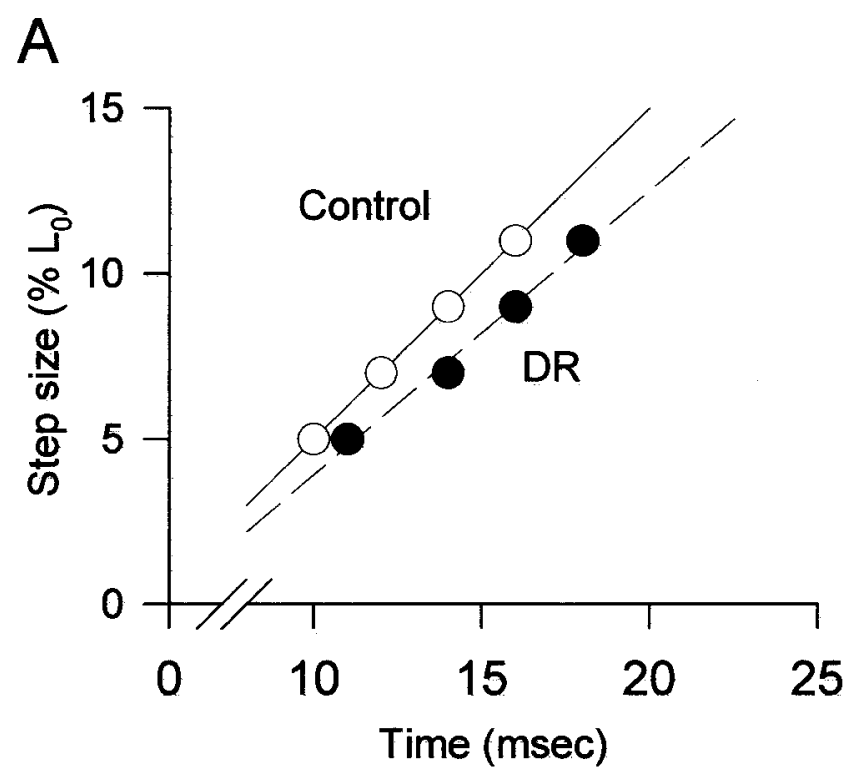

B

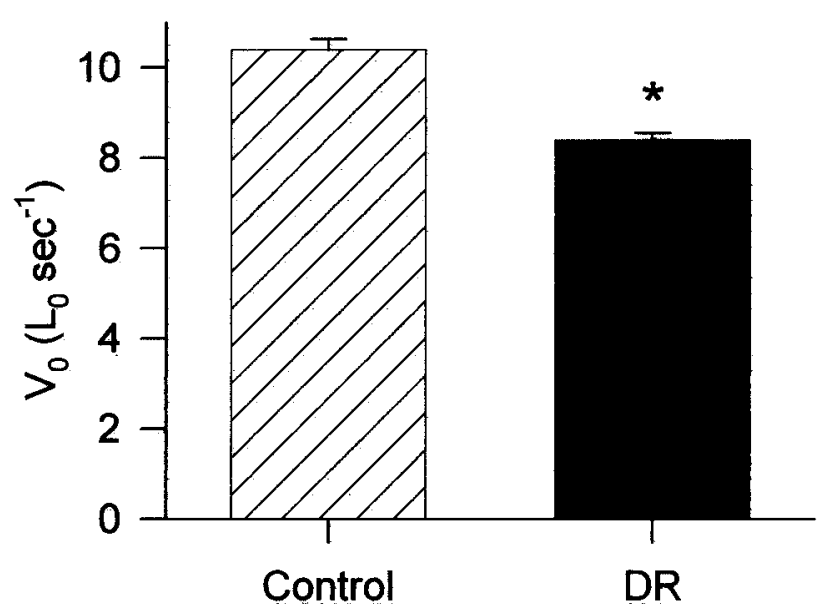

Figure 4. A, Plot of the amplitude of the shortening step versus the time to take up the slack and redevelop force. Extraocular muscles from dark-reared mice (DR; black circles) had longer times than muscles from control animals (Control; white circles); therefore, the linear regression of the DR data points (dashed line) has a lower slope (slower $V_{0}$ ) than the regression through the control points (solid line). $B$, Mean $V_{0}$ is faster in extraocular muscles from control mice than in dark-reared (DR) mice; $n=10$ muscles/group. *DR significantly different from control, $p<0.001$.

retina, preventing degradation of vision during movements of the head in space. aVOR and OKR gains were reduced, as has been reported in the dark-reared rabbit, the only other afoveate species in which the functional effects of dark rearing have been explored (Collewijn, 1977a; Favilla et al., 1984). Unlike the rabbit, the mouse exhibited an abnormally large phase lead in the aVOR. The greater lead might arise if the brainstem neural integrator [responsible for generating the tonic firing rates required to maintain stable eccentric eye positions and offsetting phaseleading tendencies of the aVOR circuit (Skavenski and Robinson, 1973; Robinson, 1981)] fails to develop normally in the absence of visual feedback. The reduction of OKR and aVOR gains is evidence that dark rearing altered ocular motor function, although the qualitative preservation of compensatory eye movements indicates that this intervention did not derange the underlying neuronal circuitry entirely. VOR preservation indicates that 
A

B

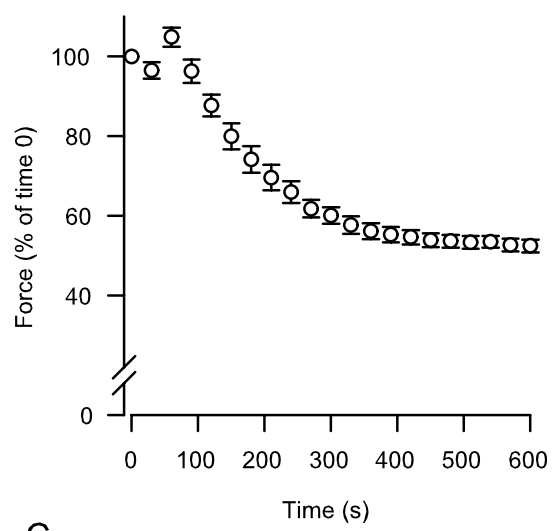

C

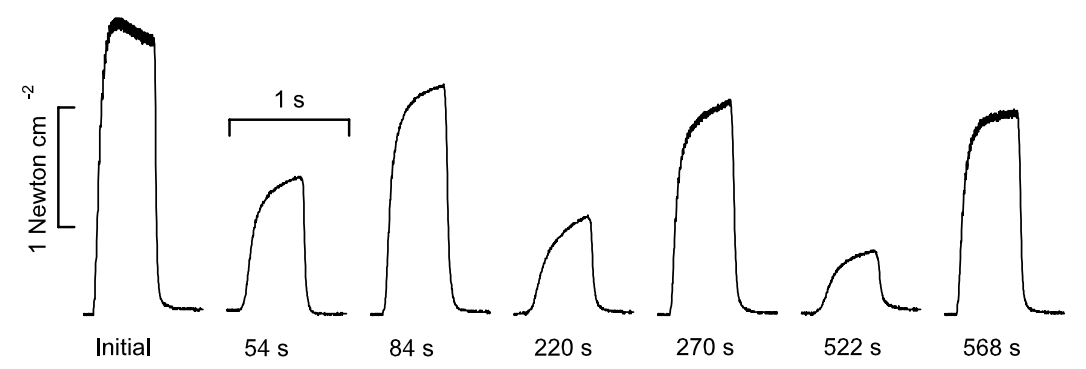

Figure 5. $A$, Changes in force during fatigue for control extraocular muscles $(n=10)$. Data are mean force \pm SEM determined every $30 \mathrm{sec}$ for the duration of the fatigue protocol. $B$, Responses to fatigue of the extraocular muscles from dark-reared mice. Data are peak force of tetani measured every $10 \mathrm{sec}$. One pattern was similar to the typical response of control muscles (one muscle, black circles). Another pattern (two muscles, white triangles) was an early large force drop to a low plateau. The most common pattern (7 of 10 muscles) was fluctuations in force amplitude (seesaw). This pattern is exemplified by the black line showing the response of one muscle. C, Original records of tetani at selected time points during the fatigue protocol of an extraocular muscle from a dark-reared mouse. Tetani demonstrate the seesaw pattern of force amplitude seen in most extraocular muscles from this group.

mice moved their eyes throughout the dark-rearing period; the in vivo findings cannot be attributed to simple disuse of the extraocular muscles. Moreover, the reduction in OKR and aVOR gains is probably not attributable to contractile deficits because nystagmus fast phases, which require greater muscle force (see below), exhibited normal velocity/amplitude characteristics.

Rapid eye movements such as saccades and fast phases of nystagmus make the greatest demands on the extraocular muscles in terms of peak force levels, a consequence of the viscoelastic properties of the eyeball and orbital tissues (Leigh and Zee, 1999). Normal rapid eye movements exhibit a tight relationship between peak eye velocity and eye movement amplitude ("velocity/ amplitude" or "main sequence" relationship). Functionally significant reductions in contractility would be expected to manifest first as a slowing of saccades, detected in these experiments as a reduction in the slopes of the velocity/amplitude relationships. However, despite the in vitro alterations in extraocular muscle function demonstrated above, there was no change in the velocity/amplitude slopes. Absence of change may be explained in several ways. First, the alterations observed in vitro may not apply when extraocular muscles are activated naturally in vivo. Second, the in vitro alterations may be of insufficient magnitude to drop force below the level normally developed during fast phases of nystagmus. Third, adaptive modifications in the neural circuitry underlying fast phases may compensate for contractile defects. Choosing between these possibilities requires further study of the mechanical properties of the mouse orbit as well as recordings of motoneuron firing rates during fast phases.
To our knowledge this is the first report of velocity/amplitude relationships in the mouse. As in other species that have been studied, peak velocity and amplitude of fast phases were tightly correlated. The relationship was linear as opposed to saturating. Peak velocities in the mouse possibly could saturate at amplitudes higher than we were able to elicit, but the departure from linearity probably lies well above the values reported in other species. The confidence intervals in Figure 1 indicate that peak velocities in humans depart from a linear relationship above $200 \% \mathrm{sec}$. The linear range in the rabbit extends to $\sim 35^{\circ}$, corresponding to $\sim 400^{\circ} / \mathrm{sec}$ (Collewijn, 1977b). In contrast, we commonly recorded mouse fast phases with peak velocities in excess of $500 \%$ sec that fell on the linear velocity/amplitude relationship.

\section{Light deprivation delays oculomotor maturation}

Genome-wide expression profiling demonstrated that dark rearing induces a state of flux in the oculomotor nuclei; genes preferentially expressed during neuronal development and plasticity were upregulated (Fig. 3, Table 1). By combining the microarray studies with in vivo and in vitro assessments of ocular motor function, we achieved a more integrative view of how the ocular motor system responds to abnormal sensory input during the critical period. The physiological data indicated that dark rearing impaired extraocular muscle function and the "tuning" of neural mechanisms underlying compensatory eye movements. The upregulation of genes known to be related to neuronal plasticity might reflect a process by which central mechanisms compensate for the peripheral abnormality. Alternatively, absence of visual experience simultaneously could thwart the acquisition of normal eye movement tuning and perpetuate an immature and unstable transcriptome by preventing the achievement of the adult state.

The power of genome-wide expression profiling lies on the detection of pattern shifts, not on measuring changes in selected genes. Our data do not indicate which genes, clusters, or functional classes may be mechanistically more important to achieve the final state. However, the use of multiple samples per treatment, a focus on the overall pattern, and a conservative data analysis strategy give confidence in the robustness of the results. In addition, we independently confirmed the expression changes of 15 of 132 altered genes by qPCR. Still, limitations inherent in the experimental design need to be acknowledged. First, we do not know how the oculomotor gene expression profile evolved during the 8 weeks of dark rearing. Our study provides a snapshot of the final result; hence it is beyond its scope to resolve whether experience-dependent genes guide the establishment of the normal adult profile. The same limitation applies to the eye movement studies: at what point ocular motor function becomes abnormal in dark-reared animals cannot be determined. The dimensionality of the gene expression profile could not be reduced statistically; PCA did not identify gene groups that may 
have influenced the variance to a greater extent than others. Still, the emerging pattern presented by our data is one of a plastic system that potentially could continue to full adult status with the restoration of normal lighting conditions.

\section{Light deprivation alters extraocular muscle function Functional deficits}

Dark rearing induced a $10-20 \%$ decrease in $P_{0}$ and $V_{0}$ of mouse extraocular muscles. Because the mice were moving freely in their cages during the 8 wk duration of dark rearing, their eyes must have moved in response to vestibular stimuli; in consequence, the contractile deficits were not likely attributable to disuse atrophy. As previously mentioned, it may seem surprising that the loss of muscle force and speed did not alter peak eye velocity in vivo (Fig. 1 ), but it must be realized that the in vitro measurements define only the functional limits of the extraocular muscles; such extremes may not be required in the intact animal to execute fast phases with normal velocity/amplitude relationships. In other words, there is excess contractile capacity that is not taxed by the eye movement behaviors that were tested. For example, $P_{0}$ is the force produced by fully fused tetani in response to supramaximal stimulation frequencies. However, motor systems work at frequencies much lower than these (Hennig and Lømo, 1985). If dark rearing results in weaker motor units, this deficit could be offset by increasing stimulation frequency and/or motor unit recruitment. The difference between in vitro activation and natural recruitment of extraocular muscle fibers also may explain the lack of an in vivo correlate for the impaired $V_{0}$. In heterogeneous muscles, such as the extraocular muscles, $V_{0}$ is a measure of the speed of shortening of the fastest muscle fibers present (Claflin and Faulkner, 1985). In the extraocular muscles these fibers should be those expressing the ultrafast extraocular musclespecific myosin isoform, i.e., the orbital singly innervated fibers (OSIF). But OSIF may not govern peak eye velocity in vivo, based on observations that impaired OSIF function does not alter eye movement velocity (Stahl et al., 1998).

\section{Contractile failure during fatigue}

Most extraocular muscles from dark-reared mice generated fluctuating force during the fatigue protocol. These variations occurred on a time scale of seconds; the waveform of individual tetani was normal (Fig. 5C). This phenomenon resembled fastonset short-term "high-frequency" fatigue (Westerblad et al., 1991). Alternating changes in force amplitude may represent episodes of activation failure in selected fibers that occurred as fatigue set in and likely are attributable to loss of sarcolemmal excitability. In other words, these extraocular muscle fibers became temporarily unexcitable, causing rapid drops in force. Once the fibers "rested" and regained excitability, force rebounded rapidly. The two extraocular muscles in the dark-reared group with early force decreases (e.g., white triangles in Fig. 5B) may be extreme examples of the same phenomenon; the fibers did not recover and force remained depressed for the duration of the protocol. These results suggest that dark rearing altered the excitability of extraocular muscle fibers.

\section{Conclusion}

This study is the first to demonstrate the effects of sensory deprivation on murine ocular motor function and gene expression. Our data indicate that visual experience early in life is necessary for the normal development of the mouse ocular motor system and its motor plant. Dark rearing induces a genetic state of arrested/delayed development in oculomotor nuclei and a failure to acquire a normal pattern of compensatory eye movement dynamics. However, the ocular motor system still can compensate for altered extraocular muscle function. The arrested development may indicate that vision is required for the achievement of an adult transcriptional pattern, or it may reflect an ongoing process by which the brain attempts to compensate for abnormal extraocular muscles.

\section{References}

Abe K, Rossman KL, Liu B, Ritola KD, Chiang D, Campbell SL, Burridge K, Der CJ (2000) Vav2 is an activator of Cdc42, Rac1, and RhoA. J Biol Chem 275:10141-10149.

Baloh RW, Sills AW, Kumley WE, Honrubia V (1975) Quantitative measurements of saccade amplitude, duration, and velocity. Neurology 25:1065-1070.

Bass BL (2002) RNA editing by adenosine deaminases that act on RNA. Annu Rev Biochem 71:817-846.

Baxter RG, Martin JE, Pullen AH (2002) Reduced neuronal nitric oxide synthase (NOS1) antigen in sacral motor neurons in motor neuron disease. Acta Neuropathol (Berl) 104:391-397.

Berardi N, Pizzorusso T, Maffei L (2000) Critical periods during sensory development. Curr Opin Neurobiol 10:138-145.

Bhattacharya S, Stewart BA, Niemeyer BA, Burgess RW, McCabe BD, Lin P, Boulianne G, O'Kane CJ, Schwartz TL (2002) Members of the synaptobrevin/vesicle-associated membrane protein (VAMP) family in Drosophila are functionally interchangeable in vivo for neurotransmitter release and cell viability. Proc Natl Acad Sci USA 99: 13867-13872.

Bloor DJ, Metcalfe AD, Rutherford A, Brison DR, Kimber SJ (2002) Expression of cell adhesion molecules during human preimplantation embryo development. Mol Hum Reprod 8:237-245.

Boghen D, Troost BT, Daroff RB, Dell'Osso LF, Birkett JE (1974) Velocity characteristics of normal human saccades. Invest Ophthalmol Vis Sci 13:619-623.

Brancolini C, Bottega S, Schneider C (1992) Gas2, a growth arrest-specific protein, is a component of the microfilament network system. J Cell Biol 117:1251-1261.

Brickley SG, Revilla V, Cull-Candy SG, Wisden W, Farrant M (2001) Adaptive regulation of neuronal excitability by a voltage-independent potassium conductance. Nature 409:88-92.

Bronstein JM, Chen K, Tiwari-Woodruff S, Kornblum HI (2000) Developmental expression of OSP/Claudin-11. J Neurosci Res 60:284-290.

Brueckner JK, Porter JD (1998) Visual system maldevelopment disrupts extraocular muscle-specific myosin expression. J Appl Physiol 85:584-592.

Brueckner JK, Ashby LP, Prichard JR, Porter JD (1999) Vestibulo-ocular pathways modulate extraocular muscle myosin expression patterns. Cell Tissue Res 295:477-484.

Bulfone A, Smiga SM, Shimamura K, Peterson A, Puelles L, Rubenstein JL (1995) T-brain-1: a homolog of Brachyury whose expression defines molecularly distinct domains within the cerebral cortex. Neuron 15:63-78.

Buratowski S (1994) The basics of basal transcription by RNA polymerase II. Cell 77:1-3.

Chae T, Kwon YT, Bronson R, Dikkes P, Li E, Tsai LH (1997) Mice lacking p35, a neuronal specific activator of Cdk5, display cortical lamination defects, seizures, and adult lethality. Neuron 18:29-42.

Chairi C, Staines W, Messier C (2002) Immunohistochemical localization and quantification of glucose transporters in the mouse brain. Neuroscience 111:19-34.

Claflin DR, Faulkner JA (1985) Shortening velocity extrapolated to zero load and unloaded shortening velocity of whole rat skeletal muscle. J Physiol (Lond) 359:357-363.

Collewijn H (1977a) Optokinetic and vestibulo-ocular reflexes in darkreared rabbits. Exp Brain Res 37:287-300.

Collewijn H (1977b) Eye- and head movements in freely moving rabbits. J Physiol (Lond) 266:471-498.

Crottet P, Meyer DM, Rohrer J, Spies M (2002) ARF1.GTP, tyrosine-based signals, and phosphatidylinositol 4,5-bisphosphate constitute a minimal machinery to recruit the AP-1 clathrin adaptor to membranes. Mol Biol Cell 13:3672-3682.

Eisen MB, Spellman PT, Brown PO, Botstein D (1998) Cluster analysis and 
display of genome-wide expression patterns. Proc Natl Acad Sci USA 95:14863-14868.

Escudero M, de Waele C, Berthoz A, Vidal PP (1993) Saccadic eye movements and the horizontal vestibulo-ocular and vestibulo-collic reflexes in the intact guinea-pig. Exp Brain Res 97:254-262.

Evinger C, Fuchs AF (1978) Saccadic, smooth pursuit, and optokinetic eye movements of the trained cat. J Physiol (Lond) 285:209-229.

Fagiolini M, Pizzorusso T, Berardi N, Domenici L, Maffei L (1994) Functional postnatal development of the rat primary visual cortex and the role of visual experience: dark rearing and monocular deprivation. Vision Res 34:709-720.

Favilla M, Ghelarducci B, La Noce A (1984) Development of vertical vestibular-ocular reflex characteristics in intact and flocculectomized rabbits visually deprived from birth. Behav Brain Res 13:209-216.

Flasza M, Gorman R, Roylance R, Canfield AE, Baron M (2002) Alternative splicing determines the domain structure of WWP1, a Nedd4 family protein. Biochem Biophys Res Commun 290:431-437.

Fuchs AF (1967) Saccadic and smooth pursuit eye movements in the monkey. J Physiol (Lond) 191:609-631.

Gall T, McPherson PS, De Camilli P (1996) The $V_{0}$ sector of the V-ATPase, synaptobrevin, and synaptophysin are associated on synaptic vesicles in a Triton X-100 resistant, freeze-thawing sensitive complex. J Biol Chem 271:2191-2199.

Giulietti A, Overbergh L, Valckx D, Decallonne B, Bouillon R, Mathieu C (2001) An overview of real-time quantitative PCR: applications to quantify cytokine gene expression. Methods 25:386-401.

Hara Y, Rovescalli AC, Kim Y, Nirenberg M (1992) Structure and evolution of four POU domain genes expressed in mouse brain. Proc Natl Acad Sci USA 89:3280-3284.

Harris LR, Cynader M (1981) Modifications of the balance and gain of the vestibulo-ocular reflex in the cat. Exp Brain Res 44:57-70.

Hashino E, Shero M, Junghans D, Rohrer H, Milbrandt J, Johnson Jr EM (2001) GDNF and neurturin are target-derived factors essential for cranial parasympathetic neuron development. Development 128:5773-5782.

Hennig R, Lømo T (1985) Firing patterns of motor units in normal rats. Nature 314:164-166.

Horie M, Suzuki M, Takahashi E, Tanigami A (1999) Cloning, expression, and chromosomal mapping of the human 14-3-3 $\gamma$ gene (YWHAG) to 7q11.23. Genomics 60:241-243.

Irobi J, Nelis E, Verhoeven K, De Vriendt E, Dierick I, De Jonghe P, Van Broeckhoven C, Timmerman V (2002) Mutation analysis of 12 candidate genes for distal hereditary motor neuropathy type II (distal HMN II) linked to 12q24.3. J Peripher Nerv Syst 7:87-95.

Jarvis SR, Barr W, Feng Z, Hamid J, Zamponi G (2002) Molecular determinants of syntaxin 1 modulation of $\mathrm{N}$-type calcium channels. J Biol Chem 277:44399-44407.

Kaminska B, Kaczmarek L, Zangenehpour S, Chaudhuri A (1999) Rapid phosphorylation of Elk-1 transcription factor and activation of MAP kinase signal transduction pathways in response to visual stimulation. Mol Cell Neurosci 13:405-414.

Lecuona E, Luquin S, Avila J, Garcia-Segura LM, Martin-Vasallo P (1996) Expression of the $\beta 1$ and $\beta 2$ (AMOG) subunits of the Na, K-ATPase in neural tissue: cellular and developmental distribution patterns. Brain Res Bull 10:167-174.

Leigh RJ, Zee DS (1999) The neurology of eye movements. New York: Oxford UP.

Lekmine F, Sassano A, Uddin S, Majchrzak B, Miura O, Drucker BJ, Fish EN, Imamoto A, Platanias LJ (2002) The CrkL adaptor protein is required for type 1 interferon-dependent gene transcription and activation of the small G-protein Rap1. Biochem Biophys Res Commun 291:744-750

Lennerstrand G, Hanson J (1979) Contractile properties of extraocular muscle in cats reared with monocular lid closure and artificial squint. Acta Ophthalmol (Copenh) 57:591-599.

Livak KJ, Schmittgen TD (2001) Analysis of relative gene expression data using real-time quantitative PCR and the $2^{\Delta \Delta C T}$ METHOD. METHODS 25:402-408.

Malaspina A, Kaushik N, de Bellroche J (2000) A 14-3-3 mRNA is upregulated in amyotrophic lateral sclerosis spinal cord. J Neurochem 75:2511-2520.

Marazziti D, Gallo A, Golini B, Matteoni T, Tocchini-Valentini GP (1998) Molecular cloning and chromosomal localization of the mouse Gpr37 gene encoding an orphan G-protein-coupled peptide receptor expressed in brain and testis. Genomics 53:315-324.

Moss J, Vaughan M (2002) Cytohesin-1 in 2001. Arch Biochem Biophys 397:156-161.

Nangaku M, Sato-Yoshitake R, Okada Y, Noda Y, Takemura R, Yamazaki H, Hirokawa N (1994) KIF1B, a novel microtubule plus end-directed monomeric motor protein for transport of mitochondria. Cell 79:1209-1220.

Niclas J, Navone F, Hom-Booher N, Vale RD (1994) Cloning and localization of a conventional kinesin motor expressed exclusively in neurons. Neuron 12:1059-1072.

Olson AL, Knight JB, Pessin JE (1997) Syntaxin 4, VAMP2, and/or VAMP3/ cellubrevin are functional target membrane and vesicle SNAP receptors for insulin stimulated GLUT4 translocation in adipocytes. Mol Cell Biol 17:2425-2435.

Orimo A, Inoue S, Ikeda K, Sato M, Kato A, Tominaga N, Suzuki M, Noda T, Watanabe M, Muramatsu M (1998) Molecular cloning, localization, and developmental expression of mouse brain finger protein (bfp)/ ZNF179: distribution of bfp mRNA partially coincides with the affected areas of Smith-Magenis syndrome. Genomics 54:59-69.

Parr BA, Cornish VA, Cybulsky ML, McMahon AP (2001) Wnt7b regulates placental development in mice. Dev Biol 237:324-332.

Payne RM, Strauss AW (1994) Developmental expression of sarcomeric and ubiquitous mitochondrial creatine kinase is tissue-specific. Biochim Biophys Acta 1219:33-38.

Petersen SL, Curran MA, Marconi SA, Carpenter CD, Lubbers LS, McAbee MD (2000) Distribution of mRNAs encoding the arylhydrocarbon receptor, arylhydrocarbon receptor nuclear translocator, and arylhydrocarbon receptor nuclear translocator-2 in the rat brain and brainstem. J Comp Neurol 427:428-439.

Poirier F, Chan CT, Timmons PM, Robertson EJ, Evans MJ, Rigby PW (1991) The murine H19 gene is activated during embryonic stem cell differentiation in vitro and at the time of implantation in the developing embryo. Development 113:1105-1114.

Porter JD, Khanna S, Kaminski HJ, Rao JS, Merriam AP, Richmonds CR, Leahy P, Li J, Andrade FH (2001) Extraocular muscle is defined by a fundamentally distinct gene expression profile. Proc Natl Acad Sci USA 98:12062-12067.

Prieschl EE, Novotny V, Csonga R, Jaksche D, Elbe-Buger A, Thumb W, Auer M, Stingl G, Baumruker T (1998) A novel splice variant of the transcription factor Nrfl interacts with the TNF $\alpha$ promoter and stimulates transcription. Nucleic Acids Res 26:2291-2297.

Quetglas S, Ibarra C, Sasakawa N, De Haro L, Kumakara K, Leveque C, Seagar M (2002) Calmodulin and lipid binding to synaptobrevin regulates calcium-dependent exocytosis. EMBO J 21:3970-3979.

Robinson DA (1981) The use of control systems analysis in the neurophysiology of eye movements. Annu Rev Neurosci 4:463-503.

Seol W, Choi HS, Moore DD (1995) Isolation of proteins that interact specifically with the retinoid $\mathrm{X}$ receptor: two novel orphan receptors. Mol Endocrinol 9:72-85

Skavenski AA, Robinson DA (1973) Role of abducens neurons in vestibuloocular reflex. J Neurophysiol 36:724-738.

Stahl JS (2002) Calcium channelopathy mutants and their role in ocular motor research. Ann NY Acad Sci 956:64-74.

Stahl JS, Averbuch-Heller L, Remler BF, Leigh RJ (1998) Clinical evidence of extraocular muscle fiber-type specificity of botulinum toxin. Neurology 51:1093-1099.

Stahl JS, van Alphen AM, De Zeeuw CI (2000) A comparison of video and magnetic search coil recordings of mouse eye movements. J Neurosci Methods 99:101-110.

Takahashi S, Yamamoto H, Matsuda Z, Ogawa M, Yagyu K, Taniguchi T, Miyata T, Kaba H, Higuchi T, Okutani F, Fujimoto S (1995) Identification of two highly homologous presynaptic proteins distinctly localized at the dendritic and somatic synapses. FEBS Lett 368:455-460.

Tusa RJ, Mustari MJ, Burrows AF, Fuchs AF (2001) Gaze-stabilizing deficits and latent nystagmus in monkeys with brief, early-onset visual deprivation: eye movement recordings. J Neurophysiol 86:651-661.

Westerblad H, Lee JA, Lännergren J, Allen DG (1991) Cellular mechanisms of fatigue in skeletal muscle. Am J Physiol 261:C195-C209.

Yamazaki M, Mori H, Araki K, Mori KJ, Mishina M (1992) Cloning, expression, and modulation of a mouse NMDA receptor subunit. FEBS Lett $300: 39-45$ 